\title{
Confinement to the intrapancreatic bile duct is independently associated with a better prognosis in extrahepatic cholangiocarcinoma
}

\author{
Keun Soo Ahn ${ }^{1}$, Koo Jeong Kang ${ }^{1 *}$ (D), Yu Na Kang ${ }^{2}$, Yong Hoon Kim ${ }^{1}$ and Tae-Seok Kim ${ }^{1}$
}

\begin{abstract}
Background: Actual differences of long term outcome of extrahepatic cholangiocarcinoma according to the location of the tumor have not yet been studied. The aim of this study was to evaluate the prognosis and optimal surgical procedure for middle (BD) cancer.

Methods: Among 109 patients with carcinoma of the extrahepatic BD underwent surgical resection, curative resection of extrahepatic BD cancer was performed in 90 patients. They were classified into three groups according to the location of tumors: DISTAL $(n=32)$, tumor was confined to the intrapancreatic bile duct; MID $(n=20)$, tumor was located between below the confluence of the hepatic duct bifurcation and suprapancreatic portion of the BD; and DIFFUSE $(n=38)$, tumor was located diffusely.

Results: Tumor involving the middle BD (MID or DIFFUSE) had a higher rate of perineural invasion as compared to the DISTAL group. The overall and disease-free survival rate for the MID or DIFFUSE group was significantly worse than that of DISTAL. In the MID/DIFFUSE group, there was no significant difference of survival according to the type of the operation (pancreaticoduodenectomy or segmental BD resection). The multivariate analysis showed that tumor involving middle BD (MID or DIFFUSE group) and node metastasis were independently poor prognostic factors for the disease free and overall survival.

Conclusion: Extrahepatic cholangiocarcinoma involving the extrapancreatic BD has a worse prognosis than those confined to the intrapancreatic $\mathrm{BD}$. In patients with tumors confined to the middle $\mathrm{BD}, \mathrm{BD}$ resection can be considered as an alternative surgical procedure to pancreaticoduodenectomy, if an Ro resection can be accomplished.
\end{abstract}

Keywords: Extrahepatic cholangiocarcinoma, Location, Prognosis

\section{Background}

Extrahepatic cholangiocarcionoma is classified into perihilar cholangiocarcinoma and distal bile duct (BD) cancer according to the anatomical location of the tumor as defined in the $7^{\text {th }}$ edition of American Joint Committee on Cancer's (AJCC) classification [1, 2]. For convenience, distal BD cancer has been further subdivided into middle BD carcinoma, which is defined as the infrahilar/

\footnotetext{
* Correspondence: kjkang@dsmc.or.kr

${ }^{1}$ Department of Surgery, Keimyung University School of Medicine, Dongsan Medical Center, 56 Dalsung-ro, Jung-gu, Daegu City, Republic of Korea Full list of author information is available at the end of the article
}

suprapancreatic area (or from the confluence of cystic duct to the superior border of pancreas) and distal $\mathrm{BD}$ cancer, which is referred to as intrapancreatic BD [3-6]. However, an exact location of the middle BD is difficult to define because of different locations of the cystic duct confluence. Additionally, tumors are rarely confined to one segment (proximal, middle, or distal BD) microscopically, and bile duct cancer tends to spread along the bile duct epithelium longitudinally, rather be than confined to one area $[2,7,8]$. While there are different operative approaches between hilar cholangiocarcionma and extrahepatic bile duct cancer, pancreaticodudenectomy (PD) 
has been regarded as a standard operative procedure for mid and distal BD cancer, although segmental BD resection can be applied in limited patients. For these reasons, in recent literature, middle and distal BD cancer were classified together as 'distal bile duct' cancer and have a same AJCC $7^{\text {th }}$ classification.

However, middle BD cancer has a different behavior when compared to distal BD cancer. In cancer confined to the intrapancreatic portion, periampullary structures, such as the pancreas or duodenum, may limit the tumor spread into adjacent tissues. In contrast, cancer located in the middle BD may have a higher possibility of earlier microscopic tumor invasion of the periductal structure in the hepatodudenal ligament. This may affect the encasement of the adjacent hepatic artery or portal vein earlier, and result in a higher chance of radial margin involvement. However, although the possibility of poor outcomes in middle CBD cancer have been suggested, actual differences of long term outcome according to the location have not yet been studied [5, 9-13] and the study which showed prognostic impact of the primary tumor site is rare [14]. Furthermore, the appropriate operative procedure for tumors confined to the middle $\mathrm{BD}$ has not been fully defined. Although usually, PD is needed for curative resection in mid BD cancer, there has been debate about whether segmental resection of the bile duct can be an alternative treatment or not when negative margins can be obtained [15].

Our hypothesis was that BD cancer involving the middle $\mathrm{BD}$, may show a worse prognosis than cancer confined to the intrapancreatic BD. For the treatment of cancer confined to the mid $\mathrm{BD}$, the type of surgical procedure (PD or segmental resection of $\mathrm{BD}$ ) may not affect the survival because tumor location in the mid BD may be significantly poor prognostic factor regardless of operative type. If this is true, segmental resection of the $\mathrm{BD}$ in tumors confined to the mid BD would be justified. Therefore, the aim of this study was to analyze the clinicopathological factors that influence the survival of extrahepatic $\mathrm{BD}$ cancer according to the location of the tumor, and to determine the oncologic safety of segmental $\mathrm{BD}$ resection as an optimal surgical procedure for a cancer confined to the middle BD.

\section{Method}

\section{Population and study design}

From March 2000 to August 2012, 110 patients with adenocarcinoma of the distal BD underwent surgical resection at the Keimyung University Dongsan Medical Center. Eighteen of the patients were unable to undergo curative R0 resection; they either underwent an R1 or $\mathrm{R} 2$ resection or had distant metastases. These patients and additional two patients with in-hospital mortality were excluded. The remaining 90 patients who had extrahepatic cholangiocarcinoma originating from the middle or distal bile duct histologically confirmed with negative longitudinal or radial margin (R0) were enrolled in this study. The 90 patients were classified into three groups according to the anatomical location of the tumor based on histopathological findings: 1) the distal BD cancer group (DISTAL group), tumor was confined to the intrapancreatic $B D 2$ ) the middle BD cancer group (MID group), tumor was located between the confluence of the hepatic duct bifurcation and suprapancreatic portion of BD; and 3) the diffuse BD cancer group (DIFFUSE group), tumor was located diffusely within the middle and intrapancreatic BD (Fig. 1). When the main tumor was located in the intrapancreatic portion of the $\mathrm{BD}$, if tumor cells were present at the mid bile duct in microscopic examination, the lesion was classified as DIFFUSE group. Patients' demographics, perioperative outcomes, tumor histopathology, and follow-up data were analyzed retrospectively based on a prospectively recorded database. This retrospective study protocol was reviewed and approved by the institutional review board of the Keimyung University Dongsan Medical Center (11-308). The consents from patients for this retrospective study were waived by the institutional review board.

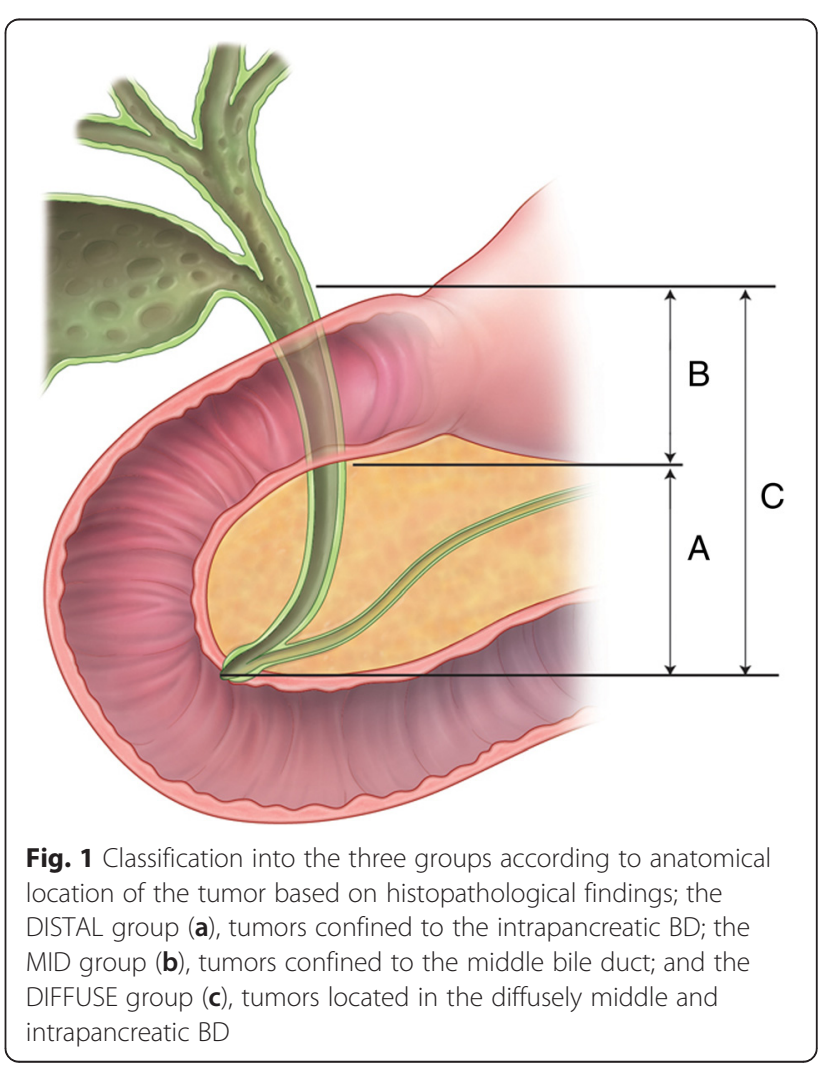


Preoperative management, surgical procedure and histopathological evaluation

There were no absolute criteria for performing preoperative biliary drainage. In general, if patients showed jaundice with bilirubin levels higher than $10 \mathrm{mg} / \mathrm{dl}$ or if a biopsy was necessary, biliary drainage endoscopically or percutaneously was performed.

The surgical procedure was determined by the extent of the lesion. All patients in the DISTAL and DIFFUSE groups underwent a standard PD or pylorus-preserving pancreaticoduodenectomy (PPPD). In the MID group, a segmental BD resection with hepaticojejunostomy was performed when a negative margin could be obtained, and PD was performed when obtaining of negative margin was not assured preoperatively or intraoperatively. A routine resection of the lymph nodes around the porta hepatis (No.12), retropancreatic (No.13), common hepatic artery and celiac trunk (No 8,9) was done.

During the study period, one pathologist reviewed the pathology to verify whether each sample was feasible for this study on the basis of the histopathologic diagnoses recorded and accumulated. Tumor stages were classified according to the $7^{\text {th }}$ edition of AJCC. Postoperative surgical complications were graded as described by the proposed Dindo-Clavien classification system [16].

\section{Follow up and diagnosis of recurrence}

The routine follow-up program consisted of a physical examination, computed tomography, and tumor markers (carcinoembryonic antigen (CEA), carbohydrate antigen (CA) 19-9) every 3 mohths for the first year, then every 6 months for the next 4 years, and thereafter, annually.

\section{Statistical analysis}

A statistical analysis were performed using SPSS, version 13.0 for Windows (SPSS,Inc., Chicago IL,USA). Comparison between the groups was performed using an independent $t$ test and ANOVA for continuous variables and Chi-square test for categorical variables. Overall and disease-free survivals were calculated using the Kaplan-Meier method. A univariate analysis of the survival curves was performed using the log-rank test. A multivariate regression analysis was performed using a Cox proportional hazards model to identify the independent prognostic factors for survival. A $P$ value of $<0.05$ was considered statistically significant.

\section{Results}

Demographic, perioperative and histopahological results

The patient population consisted of 38 women and 52 men, with a mean age of 65 years (range, 33-83 years). These patients were grouped as follows: 32 patients of the DISTAL group (35.6\%), 20 of the MID group (22.2\%) and 38 of the DIFFUSE (42.2\%). In the MID group, five patients $(25.0 \%)$ underwent PPPD, and the remaining 15 patients underwent $\mathrm{BD}$ resection. The demographic factors, perioperative results, and histopathological results showed no differences between three groups. However, a higher rate of T3 was observed in the DISTAL and DIFFUSE groups than the MID group. In the DISTAL group, rate of perineural invasion was lower than that of the MID and DIFFUSE groups (Table 1).

\section{Survival analysis according to the location, distal vs. mid} vs. diffuse, of the tumor

During the mean follow-up period of $38.8 \pm 30.0$ (range: 4.5-163.0) months, the 3- and 5- year overall survival rates for the 90 patients were 55.6 and $43.6 \%$, respectively. The 3- and 5-year disease-free survival rates were 41.6 and $29.9 \%$, respectively. The overall and disease-free survival rate for the DISTAL group was significant higher than that of the MID and DIFFUSE groups $(P=0.010$ and 0.001 , respectively. Fig. 2). The pattern of recurrence was not different among the 3 groups (Table 1).

Further survival analysis, according to the stage and presence of perineural invasion, was done among the three groups. While there was no significant survival difference among the three groups in N1 patients $(P=0.202)$, in N0 patients (including stage IIa (T3N0)), patients of the DISTAL group showed a significantly better survival rate than that of the MID and DIFFUSE group. $(P=0.010$, Fig. 3$)$ There was no significant survival difference between the DISTAL and MID/DIFFUSE groups depending on the presence of perineural invasion (Fig. 4).

\section{Survival difference according to the type of resection, segmental resection vs. PD, of the middle bile duc carcinomat}

In the MID/DIFFUSE group, there was no difference of disease-free and overall survival according to the type of procedure (PD vs. segmental $\mathrm{BD}$ resection, $P=0.808$ ). In the MID group, disease-free and overall survival was not different between PD $(n=5)$ and segmental BD resection $(n=15)(P=0.323$, Fig. 5).

\section{Prognostic factor of extrahepatic cholangiocarcinoma}

An univariate analysis showed that tumor location, gross tumor appearance, differentiation, lymph node metastasis, lymphovascular invasion, and perineural invasion were significant prognostic factors for disease-free and overall survival. The results of the multivariate analysis showed that tumor involving extrapancreatic BD and lymph node metastasis were independently poor prognostic factors for disease-free and overall survival. (Table 2). 
Table 1 Perioperative and histopathological characteristics between three groups

\begin{tabular}{|c|c|c|c|c|}
\hline & DISTAL $(n=32)$ & $\operatorname{MID}(n=20)$ & DIFFUSE $(n=38)$ & $P$ value \\
\hline Age (years) & $65.1 \pm 9.7$ & $64.3 \pm 9.6$ & $67.1 \pm 6.7$ & 0.545 \\
\hline Gender (male/female) & $18 / 14$ & $13 / 7$ & $21 / 17$ & 0.757 \\
\hline Preoperative peak TB (mg/dl) & $7.0 \pm 6.2$ & $8.9 \pm 9.4$ & $6.5 \pm 4.8$ & 0.629 \\
\hline CA $19-9 \geq 37$ & $21(70.0 \%)$ & 15 (62.0\%) & $25(68.6 \%)$ & 0.932 \\
\hline Preoperative biliary drainage (n) & $25(83.3 \%)$ & 19 (82.6 \%) & $32(84.2 \%)$ & 0.713 \\
\hline Type of resection & & & & $<0.001$ \\
\hline Pancreaticoduodenectomy & $32(100 \%)$ & $5(25.0 \%)$ & $38(100 \%)$ & \\
\hline Bile duct resection & $0(0 \%)$ & 15 (75.0\%) & $0(0 \%)$ & \\
\hline Operative time (min) & $419.0 \pm 79.8$ & $357.5 \pm 106.4$ & $421.3 \pm 69.0$ & 0.033 \\
\hline Transfusion (n) & $6(18.8 \%)$ & $2(10.0 \%)$ & $5(13.1 \%)$ & 0.524 \\
\hline Postoperative complication (n) & $14(43.8 \%)$ & $5(25.0 \%)$ & $18(47.4 \%)$ & 0.431 \\
\hline Grade $(I, I / I I I, I V)$ & $5 / 9$ & $1 / 4$ & $6 / 12$ & \\
\hline Postoperative hospital stay (days) & $29.4 \pm 13.3$ & $23.2 \pm 14.2$ & $28.6 \pm 13.1$ & 0.157 \\
\hline Gross tumor appearance & & & & 0.915 \\
\hline Infiltrating type & $26(81.3 \%)$ & $16(80.0 \%)$ & $31(81.6 \%)$ & \\
\hline Papillary/nodular type & $6(28.7 \%)$ & $4(20.0 \%)$ & 7 (18.4 \%) & \\
\hline Differentiation & & & & 0.295 \\
\hline WD & $7(21.9 \%)$ & $5(25.0 \%)$ & $6(15.8 \%)$ & \\
\hline MD & $18(56.3 \%)$ & $6(30.0 \%)$ & $21(55.3 \%)$ & \\
\hline PD & 7 (21.9 \%) & $9(45.0 \%)$ & 11 (28.9\%) & \\
\hline Depth of invasion & & & & $0.002^{\mathrm{a}}$ \\
\hline $\mathrm{T} 1$ & $5(15.6 \%)$ & $6(30.0 \%)$ & 9 (23.7\%) & \\
\hline $\mathrm{T} 2$ & $3(9.4 \%)$ & $9(45.0 \%)$ & $4(10.5 \%)$ & \\
\hline T3 & $24(75.0 \%)$ & $5(25.0 \%)$ & $25(65.8 \%)$ & \\
\hline Lymph node metastases & $10(31.3 \%)$ & $11(55.0 \%)$ & $13(34.2 \%)$ & 0.191 \\
\hline Stage (AJCC $7^{\text {th }}$ ) & & & & 0.631 \\
\hline $\mathrm{la} / \mathrm{lb}$ & $6(18.7 \%)$ & $9(45.0 \%)$ & $9(23.7 \%)$ & \\
\hline$\| \mathrm{la} / \mathrm{llb}$ & $26(81.6 \%)$ & $11(55.0 \%)$ & $29(76.3 \%)$ & \\
\hline Lymphovascular invasion & $22(68.8 \%)$ & $11(55.0 \%)$ & $29(76.3 \%)$ & 0.249 \\
\hline Perineural invasion & 15 (46.9 \%) & 16 (70.0 \%) & $33(86.8 \%)$ & $0.008^{b}$ \\
\hline Recurrence (n) & $13(40.6 \%)$ & $13(65.0 \%)$ & $30(78.9 \%)$ & $0.010^{c}$ \\
\hline Pattern of initial recurrence & & & & 0.449 \\
\hline Local recurrence & $4(30.8 \%)$ & $4(30.7 \%)$ & $11(35.5 \%)$ & \\
\hline Distant metastases & $6(46.2 \%)$ & $4(30.7 \%)$ & $6(17.2 \%)$ & \\
\hline Both (local + distant metastases) & $3(23.1 \%)$ & $5(38.4 \%)$ & $14(48.3 \%)$ & \\
\hline
\end{tabular}

Abbreviation: $T B$ total bilirubin, $C A$ cancer antigen, $W D$ well differentiation, $M D$ moderate differentiation, $P D$ poor differentiation

an comparison between T2 and T3, the rate of T2 was higher and rate of T3 was lower in the MID group than those of the DISTAL and DIFFUSE groups

${ }^{b}$ The rate of perineural invasion was lower in the DISTAL group than that of the MID and DIFFUSE groups

'The rate of recurrence was lower in the DISTAL group than that of the MID and DIFFUSe groups

\section{Discussion}

In the present study, patients with extrahepatic cholangiocarcinoma confined to the intrapancreatic portion of BD (DISTAL group) had better survival than those tumors involving the extrapancreatic BD (MID and DIFFUSE group) and it was independent prognostic factor. In the MID/DIFFUSE group, perineural invasion was significantly more frequent. The perineural space is believed to be a separate channel from the lymphatic system, and it can act as a route for tumor metastasis [17]. Clinically, several studies showed that, in patients with biliary tract cancer, including extrahepatic and intrahepatic cholangiocarcionoma and GB cancer, perineural invasion is a significantly poor prognostic factor [18-20]. 

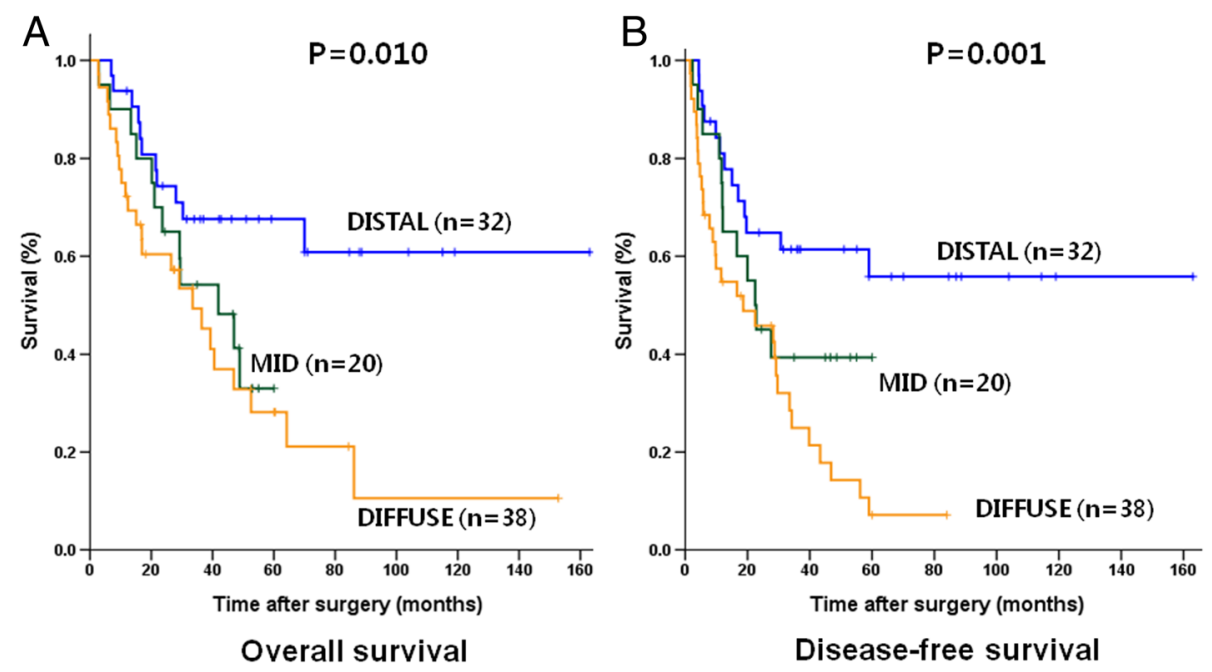

Fig. 2 Overall (a) and disease-free survival (b) in the 3 groups

In tumors involving the mid $\mathrm{BD}$, the tumor may infiltrate the adjacent structures in the hepatoduodenal ligament via neural pathways easily, and the rate of perineural invasion may be more frequent. Invasion of cancer into this area can progress to the surrounding structures, including regional lymph nodes, Glisson's sheath of the liver, and para-aortic fatty tissue. However, in tumors confined to the intrapancreatic BD, the pancreas or duodenum can act as a barrier of invasion to the surrounding perineural space, and this may be related to the less frequent perineural invasion in the IPBD group. In the present study, although perineural invasion was a significant prognostic factor under the univariate analysis, it was not an independent significant prognostic factor in multivariate analysis. The survival rate between DISTAL and MID/DIFFUSE according to the perineural invasion was not different (Fig. 4). Therefore, perineural invasion may be related to the location of the tumor, and more frequent perineural invasion in the MID/DIFFUSE group may result in a worse prognosis than that of the DISTAL group.

The other factor of different prognosis according to the tumor location is the T stage. Different survival according to the IIa (T3N0) stage between the two groups (Fig. 3) can be explained by the different anatomic structures in the different portions of the extrahepatic BD. Under the current staging system, even if tumors of the distal and middle BD have the same numeric depth of invasion, the $\mathrm{T}$ stage is staged differently. Whereas in distal BD cancer, the bile duct is within the head of the pancreas and duodenum; in mid BD cancer, adjacent organs such as the gallbladder, pancreas, and duodenum

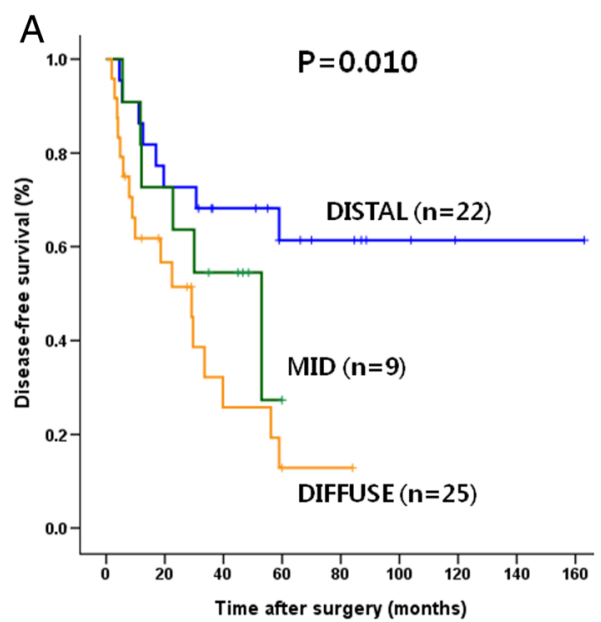

No lymph node metastasis

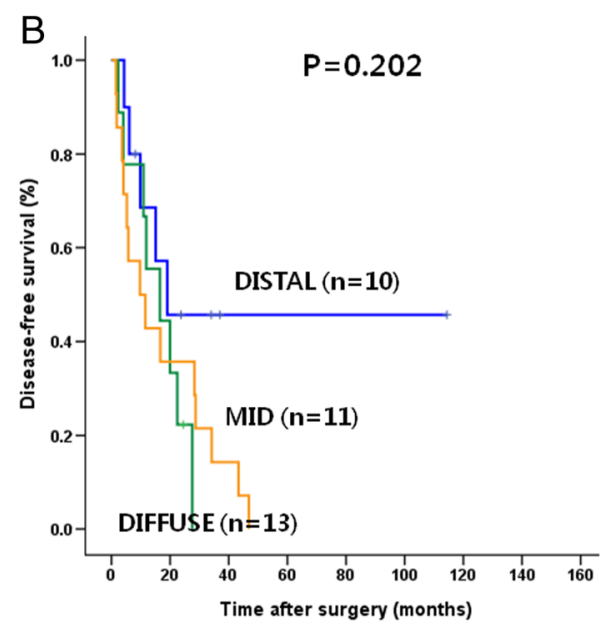

Presence of lymph node metastasis

Fig. 3 Comparison of the overall survival rates between the DISTAL and the MID/DIFFUSE in Ila (T3NO; a) and IIb (AnyTN1; b) stage 


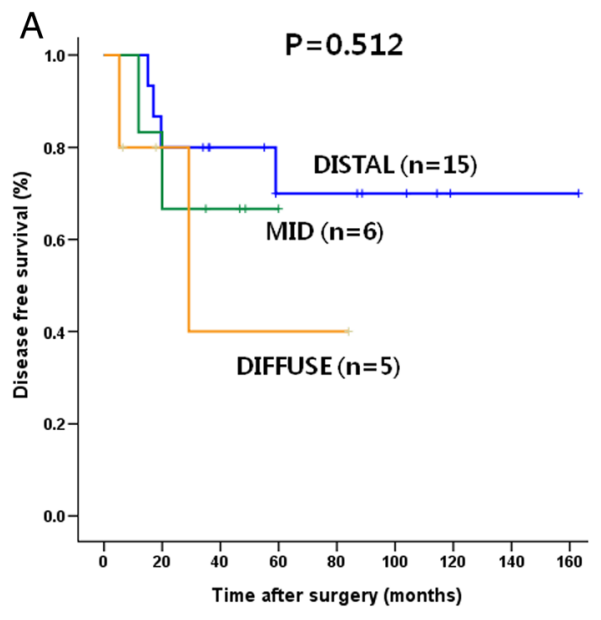

No perineural invasion

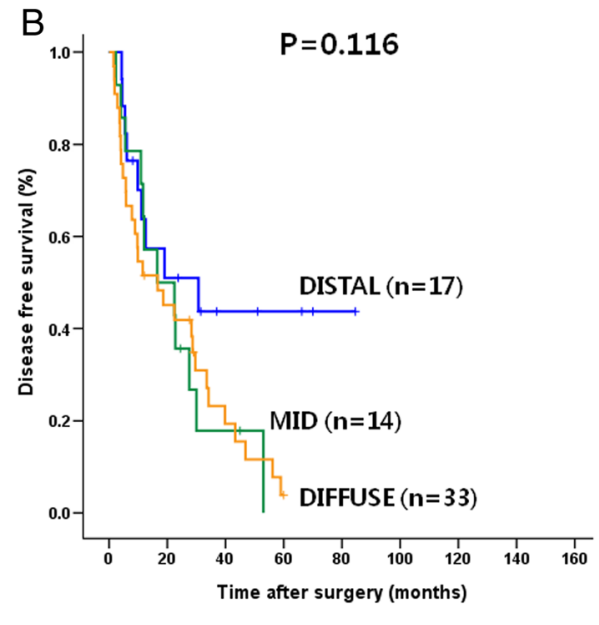

Presence of perineural invasion

Fig. 4 Comparison of the overall survival rates between the DISTAL and the MID/DIFFUSE in presence of perineural invasion (a; Absence of perineural invasion, $\mathbf{b}$; Presence of perineural invasion)

are far from the BD [21, 22]. A mid BD cancer with the extended pericholedochal soft tissue can be staged as T2 (beyond the wall), while a tumor of the same depth of invasion can be staged as T3 in the distal BD due to invasion of the pancreas. Therefore, a T2 stage of tumor in mid BD cancer may be classified as T3 in distal BD cancer in spite of the same numeric depth of invasion (Fig. 6). A few reports revealed that pancreatic and duodenal invasion does not significantly affect the survival if curative resection is performed [11]. Moreover, smooth muscle fibers in the distal BD have a tendency to form either a continuous or an interrupted layer; whereas, the mid portion of the BD generally has no fibers or only

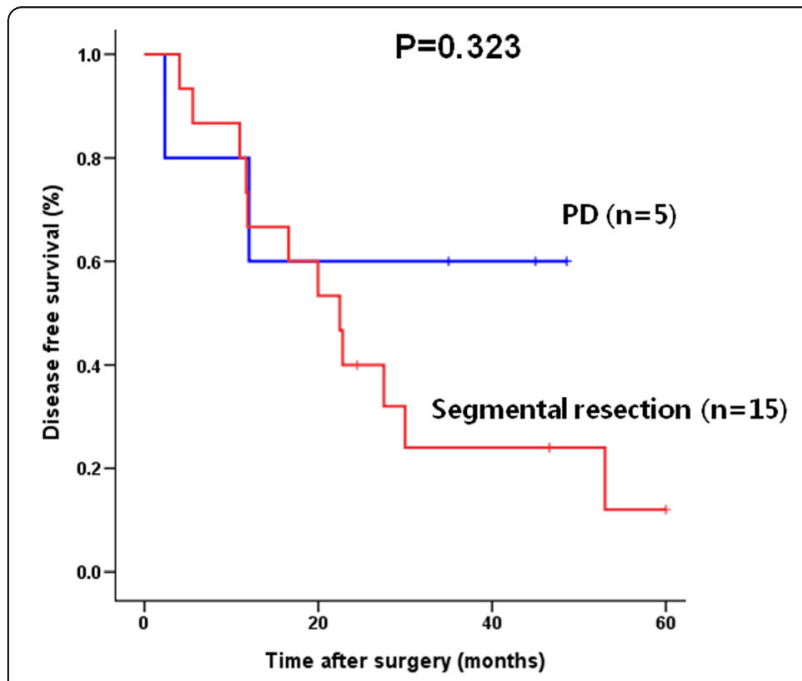

Fig. 5 Comparison of the overall survival rates in the MID/ DIFFUSE groups according to the type of operation (PD(pancreaticoduodenectomy) vs segmental bile duct resection) scattered muscle fibers. This thicker smooth muscle bundle of distal $\mathrm{BD}$ can also affect the discrepancy of $\mathrm{T}$ staging in mid and distal BD cancers [21, 22]. Considering these factors, there is a possibility of $\mathrm{T}$ stage underestimation in mid $\mathrm{BD}$ cancer compared to distal $\mathrm{BD}$ cancer in the same numeric length of the depth of invasion [21]. Therefore, the necessity of alternative $\mathrm{T}$ staging has been suggested measuring the actual depth of invasion on a millimeter scale regardless of the adjacent organ invasion to more accurately stage the cancer [21, 23, 24].

In the present study, lymph node positivity, one of the significant prognostic factors [25] in a multivariate analysis, was not related to the location of the tumor. Whereas there was no significant survival difference between the DISTAL and MID/DIFFUSE groups in N1 patients (stage IIb), there was a significance regarding better survival in the DISTAL group in N0 patients (Fig. 3). Therefore, in N0 patients, impact of tumor location and perineural invasion may be magnified in survival.

Our study showed different survival results according to the location of the $\mathrm{BD}$ using a different approach. First, we classified extrahepatic BD cancer as DISTAL (confined to intrapancreatic BD) and MID/DIFFUSE (involving extrapancreatic BD). Previous studies have classified middle $\mathrm{BD}$ cancer as tumors confined to the mid BD (MID group in our study) which could be treated with $\mathrm{BD}$ resection, and distal $\mathrm{BD}$ cancer as involvement with the intrapancreatic portion of the $\mathrm{BD}$ or diffuse BD cancer (DISTAL and DIFFUSE group in this study), in which PD was necessary $[9,15]$. In others, tumors were classified by the predominant location of the tumor without considering diffuse bile duct cancer, 
Table 2 Univariate and multivariate analysis of prognostic factors for overall survival

\begin{tabular}{|c|c|c|c|c|c|}
\hline \multirow[t]{2}{*}{ Variable } & \multicolumn{2}{|c|}{ 5-year overall survival (Univariate analysis) } & \multicolumn{3}{|c|}{ Multivariate analysis } \\
\hline & $\%$ & $P$ & $P$ & RR & Exp \\
\hline Sex & & 0.901 & & & \\
\hline Male $(n=52)$ & $35.3 \%$ & & & & \\
\hline Female $(n=38)$ & $34.3 \%$ & & & & \\
\hline Age (years) & & 0.738 & & & \\
\hline$\leq 60(n=35)$ & $34.7 \%$ & & & & \\
\hline$>60(n=55)$ & $35.2 \%$ & & & & \\
\hline Location & & 0.004 & 0.039 & & \\
\hline DISTAL $(n=32)$ & $67.6 \%$ & & & 1 & (Reference) \\
\hline MID/DIFFUSE $(n=58)$ & $30.2 \%$ & & & 2.299 & $1.044-5.065$ \\
\hline Type of procedure & & 0.298 & & & \\
\hline PD/PPPD $(n=73)$ & $31.8 \%$ & & & & \\
\hline Bile duct resection $(n=15)$ & $26.7 \%$ & & & & \\
\hline Transfusion & & 0.808 & & & \\
\hline No $(n=77)$ & $32.1 \%$ & & & & \\
\hline Yes $(n=13)$ & $26.7 \%$ & & & & \\
\hline Postoperative complication & & 0.551 & & & \\
\hline No $(n=53)$ & $40.5 \%$ & & & & \\
\hline Yes $(n=37)$ & $33.7 \%$ & & & & \\
\hline Preoperative CA 19-9 & & 0.118 & & & \\
\hline$<37(n=30)$ & $60.4 \%$ & & & & \\
\hline$\geq 37(n=60)$ & $36.4 \%$ & & & & \\
\hline Gross tumor appearance & & 0.039 & & & \\
\hline Papillary $(n=17)$ & $55.0 \%$ & & & & \\
\hline Infiltrating $(n=73)$ & $34.2 \%$ & & & & \\
\hline Differentiation & & 0.028 & & & \\
\hline WD $(n=18)$ & $71.8 \%$ & & & & \\
\hline $\mathrm{MD} / \mathrm{PD}(n=72)$ & $34.7 \%$ & & & & \\
\hline Depth of invasion & & 0.104 & & & \\
\hline $\mathrm{T} 1(n=20)$ & $68.8 \%$ & & & & \\
\hline $\mathrm{T} 2(n=16)$ & $42.1 \%$ & & & & \\
\hline $\mathrm{T} 3(n=54)$ & $34.1 \%$ & & & & \\
\hline Node metastasis & & 0.001 & 0.007 & & \\
\hline No $(n=56)$ & $51.6 \%$ & & & 1 & (Reference) \\
\hline Yes $(n=34)$ & $20.0 \%$ & & & 2.381 & $1.267-4.475$ \\
\hline Lymphovascular invasion & & 0.050 & & & \\
\hline No $(n=28)$ & $57.2 \%$ & & & & \\
\hline Yes $(n=62)$ & $30.2 \%$ & & & & \\
\hline Perineural invasion & & 0.003 & & & \\
\hline No $(n=26)$ & $68.0 \%$ & & & & \\
\hline Yes $(n=64)$ & $33.1 \%$ & & & & \\
\hline Adjuvant CTx & & 0.432 & & & \\
\hline No $(n=59)$ & $39.4 \%$ & & & & \\
\hline Yes $(n=31)$ & $37.9 \%$ & & & & \\
\hline
\end{tabular}




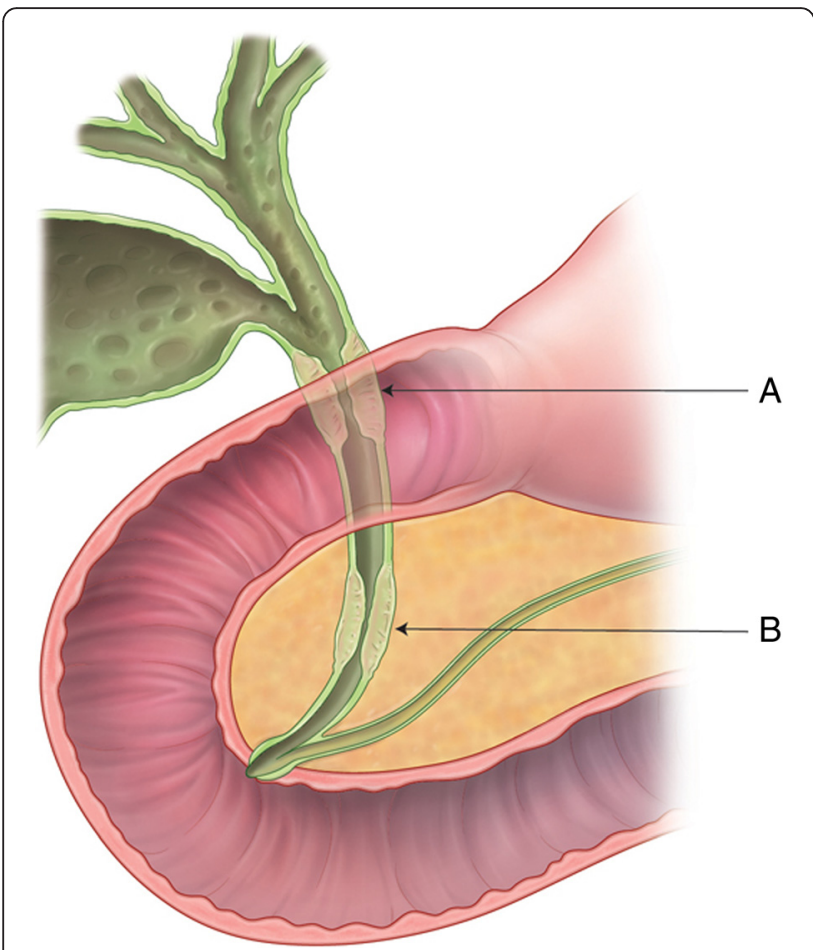

Fig. 6 An example of discrepancy of T stage according to the location. Even though two separate tumors have same depth of invasion, tumor involved middle BD cancer (A; MID/DIFFUSE group) would be classified as T2, while tumor confined to intrapancreatic portion of BD (B; DISTAL group) would be classified as T3 because of pancreas invasion

DIFFUSE in our study $[5,13]$. However, our hypothesis was that the involvement of the middle BD itself is an important poor prognostic factor and tumors confined to the middle BD would have similar prognoses to diffuse BD cancer. Therefore, our classification and analysis (DISTAL vs MID/DIFFUSE) may be more desirable to show the poor prognosis of BD cancer with involvement in the extrapancreatic BD [14]. Additionally, we included only R0 resection in this study. Recently, Kamposioras $\mathrm{K}$, et al. reported similar results with ours that common $\mathrm{BD}$ cancer involving extrapancreatic BD showed worse prognosis than tumor confined intrapancreatic BD due to higher frequency of $\mathrm{R} 1$ resection and venous resection [14]. Most patients of this study had worse tumor characteristics than present study, $74.6 \%$ of patients had lymph node metastasis and $\mathrm{R} 1$ resection was done in $71.2 \%$. These advanced tumor status maybe weaken impact of tumor location that extent of tumor involvement was not independent prognostic factor. Generally, R1 resection has been known as an independent poor prognostic predictive factor $[5,9,11,26,27]$. Therefore, excluding R1 patients in the present study is valuable to show the real impact of extrapancreatic BD involvement on prognosis. Not only excluding R0, but also less lymph node involvement in present study may magnify impact of tumor location. Although we did not focus on pathological findings, present study clinically supports the result of Kamposioras K's study.

In the tumor is confined to the middle $\mathrm{BD}$, there have been debates about whether segmental $\mathrm{BD}$ resection is an adequate operative procedure or not [6]. A few studies have shown that similar incidence of positive surgical margin and similar long-term results between segmental $\mathrm{BD}$ resection and $\mathrm{PD}$ in the cancer confined to middle $\mathrm{BD}[7,15,26,28]$. Our results showed that the clinical characteristics and long-term results between MID and DIFFUSE were not different, and the long-term results according to the operative procedure, either BD resection or PD in these groups, were also similar (Fig. 4). With BD resection, sufficient radical lymph node dissection of group 2 (numbers 8,12 , and 13) is possible and enough radial margin can be obtained [28]. Although longitundial distal margin can obtain by PPPD, extent of radial margin is similar between PPPD and bile duct resection. Poor long-term results of tumors involving the middle BD may not due to the chosen operative procedure, but involvement of the middle BD itself. Therefore, in tumors confined to the mid BD without adjacent organ invasion, PD may have no survival benefit and segmental BD resection can be safely performed if R0 resection can be accomplished.

Our study showed poor prognosis of bile duct cancer involving extrapancreatic duct. However, this study was retrospective study with small patients number, therefore, further studies with larger cases are needed to validate it.

\section{Conclusion}

In conclusion, extrahepatic cholangiocarcinoma involving the middle $\mathrm{BD}$ have a worse prognosis than those confined to intrapancreatic BD. In patients with tumors confined to the middle $\mathrm{BD}, \mathrm{BD}$ resection can be an alternative surgical procedure to $\mathrm{PD}$, if $\mathrm{R} 0$ resection can be accomplished.

\section{Abbreviations \\ BD: bile duct; PD: pancreaticoduodenectomy.}

\section{Competing interests}

The authors declare that they have no competing interests.

\section{Authors' contributions}

AKS and KKJ designed the research, KYH, KTS and KYN carried out the acquisition of data, AKS and KYH carried out analysis and interpretation of data, AKS and KKJ carried out drafting the manuscript. All authors read and approved the final manuscript.

\section{Acknowledgements}

The authors would like to express our gratitude to In Mo Kang (BS, Keimyung University School of Medicine), Hyo Jung Jang and Sung Mi Pyo (NR, Department of Surgery) for assistance of data collection. 


\section{Author details}

'Department of Surgery, Keimyung University School of Medicine, Dongsan Medical Center, 56 Dalsung-ro, Jung-gu, Daegu City, Republic of Korea. ${ }^{2}$ Department of Pathology, Keimyung University School of Medicine, Dongsan Medical Center, 56 Dalsung-ro, Jung-gu, Daegu City, Republic of Korea.

Received: 16 October 2015 Accepted: 18 February 2016

Published online: 24 February 2016

\section{References}

1. American Joint Committee on Cancer. AJCC cancer staging handbook. 7th ed. New York: Springer; 2010

2. Aljiffry M, Walsh MJ, Molinari M. Advances in diagnosis, treatment and palliation of cholangiocarcinoma: 1990-2009. World J Gastroenterol. 2009;15(34):4240-62.

3. Tompkins RK, Saunders K, Roslyn JJ, Longmire Jr WP. Changing patterns in diagnosis and management of bile duct cancer. Ann Surg. 1990; 211(5):614-20.

4. Japaneses Society of Biliary Surgery. The general rules for surgical and pathological studies on cancer of the biliary tract. 5th ed. Tokyo: Kanehara; 2003.

5. Sakamoto Y, Kosuge T, Shimada K, Sano T, Ojima H, Yamamoto J, et al. Prognostic factors of surgical resection in middle and distal bile duct cancer: an analysis of 55 patients concerning the significance of ductal and radial margins. Surgery. 2005:137(4):396-402.

6. Kondo S, Takada T, Miyazaki M, Miyakawa S, Tsukada K, Nagino M, et al. Guidelines for the management of biliary tract and ampullary carcinomas: surgical treatment. J Hepatobiliary Pancreat Surg. 2008;15(1):41-54.

7. Jang JY, Kim SW, Park DJ, Ahn YJ, Yoon YS, Choi MG, et al. Actual long-term outcome of extrahepatic bile duct cancer after surgical resection. Ann Surg. 2005;241(1):77-84.

8. Aljiffry M, Abdulelah A, Walsh M, Peltekian K, Alwayn I, Molinari M. Evidencebased approach to cholangiocarcinoma: a systematic review of the current literature. J Am Coll Surg. 2009:208(1):134-47.

9. Bahra M, Jacob D, Langrehr JM, Neumann UP, Neuhaus P. Carcinoma of the distal and middle bile duct: surgical results, prognostic factors, and longterm follow-up. J Hepatobiliary Pancreat Surg. 2008;15(5):501-7.

10. Tompkins RK, Thomas D, Wile A, Longmire Jr WP. Prognostic factors in bile duct carcinoma: analysis of 96 cases. Ann Surg. 1981;194(4):447-57.

11. Choi SB, Park SW, Kim KS, Choi JS, Lee WJ. The survival outcome and prognostic factors for middle and distal bile duct cancer following surgical resection. J Surg Oncol. 2009;99(6):335-42.

12. Kayahara M, Nagakawa T, Ohta T, Kitagawa H, Tajima H, Miwa K. Role of nodal involvement and the periductal soft-tissue margin in middle and distal bile duct cancer. Ann Surg. 1999;229(1):76-83.

13. van der Gaag NA, Kloek JJ, de Bakker JK, Musters B, Geskus RB, Busch OR, et al. Survival analysis and prognostic nomogram for patients undergoing resection of extrahepatic cholangiocarcinoma. Ann Oncol. 2012;23(10):2642-9.

14. Kamposioras K, Anthoney A, Fernandez Moro C, Cairns A, Smith AM, Liaskos $C$, et al. Impact of intrapancreatic or extrapancreatic bile duct involvement on survival following pancreatoduodenectomy for common bile duct cancer. Br J Surg. 2014;101(2):89-99.

15. Lee HG, Lee SH, Yoo DD, Paik KY, Heo JS, Choi SH, et al. Carcinoma of the middle bile duct: is bile duct segmental resection appropriate? World J Gastroenterol. 2009;15(47):5966.

16. Dindo D, Demartines N, Clavien P-A. Classification of surgical complications. Ann Surg. 2004;240(2):205-13.

17. Hassan MO, Maksem J. The prostatic perineural space and its relation to tumor spread: an ultrastructural study. Am J Surg Pathol. 1980;4(2):143-8.

18. Cho JY, Han HS, Yoon YS, Hwang DW, Jung K, Kim JH, et al. Preoperative cholangitis and metastatic lymph node have a negative impact on survival after resection of extrahepatic bile duct cancer. World I Surg. 2012;36(8):1842-7.

19. Shirai K, Ebata T, Oda K, Nishio H, Nagasaka T, Nimura Y, et al. Perineural invasion is a prognostic factor in intrahepatic cholangiocarcinoma. World J Surg. 2008;32(11):2395-402

20. Yamaguchi R, Nagino M, Oda K, Kamiya J, Uesaka K, Nimura Y. Perineural invasion has a negative impact on survival of patients with gallbladder carcinoma. Br J Surg. 2002;89(9):1130-6.
21. Hong SM, Kim MJ, Pi DY, Jo D, Cho HJ, Yu E, et al. Analysis of extrahepatic bile duct carcinomas according to the New American Joint Committee on Cancer staging system focused on tumor classification problems in 222 patients. Cancer. 2005;104(4):802-10.

22. Allen PJ, Reiner AS, Gonen M, Klimstra DK, Blumgart LH, Brennan MF, et al. Extrahepatic cholangiocarcinoma: a comparison of patients with resected proximal and distal lesions. HPB (Oxford). 2008;10(5):341-6.

23. Hong SM, Cho H, Moskaluk CA, Yu E. Measurement of the invasion depth of extrahepatic bile duct carcinoma: An alternative method overcoming the current T classification problems of the AJCC staging system. Am J Surg Pathol. 2007;31(2):199-206.

24. de Jong MC, Hong SM, Augustine MM, Goggins MG, Wolfgang CL, Hirose $\mathrm{K}$, et al. Hilar cholangiocarcinoma: tumor depth as a predictor of outcome. Arch Surg. 2011;146(6):697-703.

25. Pomianowska E, Westgaard A, Mathisen O, Clausen OP, Gladhaug IP. Prognostic relevance of number and ratio of metastatic lymph nodes in resected pancreatic, ampullary, and distal bile duct carcinomas. Ann Surg Oncol. 2013;20(1):233-41.

26. Wakai T, Shirai Y, Moroda T, Yokoyama N, Hatakeyama K. Impact of ductal resection margin status on long-term survival in patients undergoing resection for extrahepatic cholangiocarcinoma. Cancer. 2005;103(6):1210-6.

27. Ito $\mathrm{K}$, Ito H, Allen PJ, Gonen M, Klimstra D, D'Angelica MI, et al. Adequate lymph node assessment for extrahepatic bile duct adenocarcinoma. Ann Surg. 2010;251(4):675-81.

28. Sakamoto Y, Shimada K, Nara S, Esaki M, Ojima H, Sano T, et al. Surgical management of infrahilar/suprapancreatic cholangiocarcinoma: an analysis of the surgical procedures, surgical margins, and survivals of 77 patients. J Gastrointest Surg. 2010;14(2):335-43.

\section{Submit your next manuscript to BioMed Central and we will help you at every step:}

- We accept pre-submission inquiries

- Our selector tool helps you to find the most relevant journal

- We provide round the clock customer support

- Convenient online submission

- Thorough peer review

- Inclusion in PubMed and all major indexing services

- Maximum visibility for your research

Submit your manuscript at www.biomedcentral.com/submit
Biomed Central 